\title{
Brazilian Green Propolis Inhibits Ox-LDL-Stimulated Oxidative Stress in Human Umbilical Vein Endothelial Cells Partly through PI3K/Akt/mTOR-Mediated Nrf2/HO-1 Pathway
}

\author{
Wenwen Yuan, ${ }^{1}$ Huasong Chang, ${ }^{1}$ Xinying Liu, ${ }^{2}$ Shiqiang Wang, \\ Hui Liu, ${ }^{1}$ and Hongzhuan Xuan (iD) ${ }^{1}$ \\ ${ }^{1}$ School of Life Science, Liaocheng University, Liaocheng 252059, China \\ ${ }^{2}$ Center of Bee Industry on Seed-Breeding and Popularization in Shandong Province, Taian, China \\ Correspondence should be addressed to Hongzhuan Xuan; hongzhuanxuan@163.com
}

Received 21 April 2019; Revised 10 June 2019; Accepted 19 June 2019; Published 7 July 2019

Academic Editor: Miguel Vilas-Boas

Copyright (c) 2019 Wenwen Yuan et al. This is an open access article distributed under the Creative Commons Attribution License, which permits unrestricted use, distribution, and reproduction in any medium, provided the original work is properly cited.

Propolis has been widely used as a dietary supplement for its health benefits, including cardiovascular protective effects. The aim of this study was to investigate the cytoprotective effects of Brazilian green propolis (BP) against oxidized low-density lipoprotein (Ox-LDL) induced human umbilical vein endothelial cells (HUVECs) damage. Our results suggested that treatment with BP rescued Ox-LDL-stimulated HUVECs cell viability losses, which might be associated with its inhibitive effects on the cell apoptosis and autophagy. We also noticed that BP restored Ox-LDL-stimulated HUVECs oxidative stress, by induced antioxidant gene expressions, including Heme oxygenase-1 and its upstream mediator, Nrf2, which were mediated by the activation of the phosphorylation of PI3K/Akt/mTOR. Pretreatment with wortmannin, PI3K/AKT inhibitor, abolished BP induced Nrf2 nuclear translocation and HO-1 level. Our results demonstrated that BP protected HUVECs against oxidative damage partly via PI3K/Akt/mTOR-mediated Nrf/HO-1 pathway, which might be applied into preventing Ox-LDL mediated cardiovascular diseases.

\section{Introduction}

Atherosclerosis is a complex chronic inflammatory and metabolic disease, which is a consequence of oxidative stress, where homeostasis between endogenous antioxidants and reactive oxygen species is disrupted leading to lipid and protein oxidation in the vascular wall. Accumulation of lipoproteins in the vessel wall provides the initial trigger for vascular inflammation, causing endothelial dysfunction and monocyte recruitment [1]. Oxidized low-density lipoprotein (Ox-LDL) is a crucial factor in triggering the development of atherosclerosis [2]. It not only directly targets vascular endothelial cells (VECs) to induce endothelium injury or dysfunction, but can activate monocytes and macrophages by binding to scavenger receptors leading to the formation of plaque and secretion of proinflammatory cytokines $[3,4]$. A mounting evidence indicated that endothelial cells dysfunctions may be harmful to the plaque vulnerability $[5,6]$.
Thus, protecting the endothelial cells against damage or death has been considered a novel target for the atherosclerotic treatment.

Previous reports suggested that oxidative stress plays an important role in Ox-LDL induced cell damage [7]. The imbalance of redox status of a cell can cause damage to cellular components or induce cell necrosis or apoptosis, and suppressing oxidative stress has the potential to be useful in cardiovascular diseases treatment [8]. Nuclear factor erythroid 2-related factor 2 (Nrf2) is known as key modulator by upregulating of a number of detoxifying antioxidant enzymes, including heme-oxygenase-1 (HO-1), quinone oxidoreductase (NQO-1), glutathione S-transferase (GST), NAD $(\mathrm{P}) \mathrm{H}$, and $\gamma$-glutamyl cysteine synthetase catalytic subunit (GCLC) $[9,10]$. Nrf2 is distributed mainly in the cytoplasm and its translocation to the nucleus is inhibited by a Kelch-like ECHassociated protein 1 (Keap1) under normal physiological conditions. Confirmation of Keap1 changes through interacting 
with other inducers results in the release of Nrf2, which is then free to translocate into the nucleus to regulate basal antioxidant-response elements (ARE) expression including HO-1[11]. Nrf2/HO-1 axis provides a theoretical basis for the therapeutic effects against various oxidative stress-relevant diseases, through counteracting oxidative stress injury to resist inflammation, oxidation, mitochondrial damage, apoptosis, pyroptosis, and autophagy [12]. Additionally, various signaling cascades including mitogen-activated protein kinase (MAPK), phosphatidylinositol 3-kinase (PI3K/Akt), protein kinase $\mathrm{C}(\mathrm{PKC})$, c-jun $\mathrm{N}$-terminal kinase (JNK), and extracellular signal-regulated kinase (ERK) participate in Nrf2 activation [13], etc.

Propolis, a resinous material that honeybees (Apis mellifera L.) collect from various plant resources, is used widely as a health and functional food [14]. Abundant polyphenolic constituents have been identified in propolis [15]. In recent years phenolic compounds have been considered as intracellular direct antioxidants, by scavenging oxidizing species, and to exert an indirect effect, by inducing the upregulation of the synthesis of endogenous antioxidant enzymes such as superoxide dismutase, catalases, and peroxidases [16]. Our recent studies have demonstrated that propolis has shown excellent antioxidant activities, which might be attributed to the activation of PI3K/Akt/mTOR, an important signaling pathway in mediating cellular survival, proliferation, differentiation, apoptosis, and metastasis [17]. However, the relationship between Nrf2/HO-1 activation and PI3K/Akt/mTOR signal pathway on protecting endothelial cells has not been fully elucidated. The present study was designed to verify the hypothesis that Brazilian green propolis could inhibit apoptosis and autophagy induced by Ox-LDL in HUVECs by PI3K/Akt/mTOR-mediated Nrf2/HO-1 pathway.

\section{Materials and Methods}

2.1. Materials. Dulbecco's modified Eagle's medium (DMEM) and fetal bovine serum (FBS) were obtained from Gibco (USA). Sulforhodamine B (SRB), acridine orange (AO), Hoechst 33258, 2', $7^{\prime}$-dichlorodihydrofluorescin (DCHF), and JC-1 were from Sigma Co. (USA). Primary antibodies against $\beta$-actin, PI3K, and $\mathrm{p}$-PI3K were from Santa Cruz Biotechnology (USA). Primary antibodies against caspase 3, PARP, LC3B, p70S6K, p-p70S6K, p-mTOR, mTOR, Akt, p-Akt, Beclin 1, Atg7, and Nrf2 and secondary antibody (horseradish peroxidase) were from Cell Signaling Technology (USA). Primary antibodies against Bcl-2 and Bax were from ABclonal biotech (USA). Primary antibody against p62 was from BD Transduction Laboratories (USA). Primary antibody against HO-1 was from Abcam (USA). Primary antibody Lamin B was from Beyotime (China). Secondary antibody for immunofluorescence, donkey anti-rabbit IgG Alexa Fluor-488, was purchased from Life Technologies (USA). Wortmannin was obtained from Selleck (USA). OxLDL was purchased from Beijing Xiesheng Biotechnology (China). DPPH, ABTS, $\alpha$-tocopherol (Vitamin E), gallic acid, quercetin, and the standards used in HPLC analysis were purchased from Sigma (St. Louis, MO, USA). All other reagents were of ultrapure grade.
2.2. Preparation of Ethanol Extracted Brazilian Propolis. Brazilian green propolis collected in Minas Gerais State of Brazil was used in present study, where Baccharis dracunculifolia DC was the main botanical source. The extraction method was as follows. 95\% (v/v) ethanol was used to extract raw Brazilian green propolis in the dark for $24 \mathrm{~h}$ with a constant stirring. The supernatant was filtered to remove the residues. Then the solvent was evaporated in a rotary evaporator under a reduced pressure at $50^{\circ} \mathrm{C}$ until reaching a constant weight. The ethanol extracted Brazilian green propolis (EEBP) was redissolved in ethanol when it is used. The major chemical constituents were analyzed by 6510 Liquid chromatography-tandem quadrupole time of flight mass spectrometry (HPLC-DAD/Q-TOF-MS). In brief, Proshell 120SB-C18 column $(2.1 \mathrm{~mm} \times 100 \mathrm{~mm}, 2.7 \mu \mathrm{m})$ was used in the chromatographic experiments. The mobile phases used were methanol/water in gradient elution mode $(0 \sim 2$ $\min , 15 \% \sim 30 \%$; 10 25 $\mathrm{min}, 30 \% \sim 90 \%$; 25 30 $\mathrm{min}, 90 \%$; 30 $31 \mathrm{~min}, 15 \%)$. The sample injection volume was $2 \mu \mathrm{L}$, and the concentration of propolis was $10 \mathrm{mg} / \mathrm{mL}$. The column temperature was maintained at $30^{\circ} \mathrm{C}$ and the flow rate was set to $0.2 \mathrm{~mL} / \mathrm{min}$. The UV detector was set at $254 \mathrm{~nm}$. The optimal MS conditions were set as follows: electrospray ionization (ESI); flow rate and temperature were $11.0 \mathrm{~L} / \mathrm{min}$ and $350^{\circ} \mathrm{C}$; nebulizer, 40 psi, respectively.

2.3. Determination of Total Phenolic Content (TPC). The TPC was measured by the modified Folin-Ciocalten method [18]. In brief, $100 \mu \mathrm{L} \operatorname{EEBP}(300,500$, and $700 \mu \mathrm{g} / \mathrm{mL})$ was mixed with $100 \mu \mathrm{L}$ Folin-Ciocalten reagent and kept for 5 min after vortex in the dark. Then the sample was incubated with 300 $\mu \mathrm{L} 2 \%$ sodium carbonate at room temperature for $2 \mathrm{~h}$. Finally, $200 \mu \mathrm{L}$ solution was injected into 96-well plate and measured at $765 \mathrm{~nm}$. In the experiment, different concentrations of gallic acid $(0,5,10,20,40,60,80$, and $100 \mu \mathrm{g} / \mathrm{mL})$ were used as a standard and the results were expressed as gallic acid equivalent (GAE) per gram sample.

2.4. Total Flavonoids Contents (TFC). The TFC was determined by the modified method [18]. $150 \mu \mathrm{L} \operatorname{EEBP}(300,500$, and $700 \mu \mathrm{g} / \mathrm{mL}$ ) was mixed with $10 \mu \mathrm{L}$ aluminium nitrate (100 $\mathrm{g} / \mathrm{L})$ and $10 \mu \mathrm{L}$ potassium acetate $(9.8 \mathrm{~g} / \mathrm{L})$. The absorbance was measured at $415 \mathrm{~nm}$ after being incubated at room temperature for $1 \mathrm{~h}$. In the experiment, concentrations of quercetin $(4-80 \mu \mathrm{g} / \mathrm{mL})$ were used as a standard to determine TFC in EEBP. The results were expressed as milligrams quercetin equivalent per gram sample.

2.5. DPPH Radical-Scavenging Test. DPPH radical-scavenging activity of EEBP was tested by the modified method [18, 19]. Different concentrations of $\operatorname{EEBP}(70-280 \mu \mathrm{g} / \mathrm{mL})$ were prepared for the reaction. The reaction mixtures in the 96well plates consisted of the sample $(50 \mu \mathrm{L})$ and $\mathrm{DPPH}$ radicals $(50 \mu \mathrm{l}, 0.5 \mathrm{mg} / \mathrm{mL})$ dissolved in ethanol and kept in the dark for $30 \mathrm{~min}$. The absorbance was measured at $517 \mathrm{~nm}$ against a blank. All determinations were performed in triplicate. The scavenging activity of the samples was expressed as the $\mathrm{IC}_{50}$ value, the concentration required to scavenge $50 \%$ of DPPH radicals. 
2.6. ABTS Cation Radical-Scavenging Assay. The ABTS cation radical-scavenging activity assay was carried out by ABTS cation radical decolorization with minor modifications [20]. The EEBP solutions $(10-220 \mu \mathrm{g} / \mathrm{mL})$ were prepared as described for the DPPH assay. The ABTS cation radical was prepared by reacting with a $7 \mathrm{mM}$ aqueous solution of $\mathrm{ABTS}^{+}$ $(7.5 \mathrm{~mL})$ with $140 \mathrm{mM}$ potassium persulphate $(132 \mu \mathrm{L})$. The mixture was allowed to stand in the dark at room temperature for $16 \mathrm{~h}$ before use. Prior to the assays, the ABTS working reagent was diluted with ethanol to give an absorbance of $0.85 \pm 05$ at $734 \mathrm{~nm}$ after equilibration at room temperature. The reaction mixtures in the 96-well plates consisted of the sample $(50 \mu \mathrm{L})$ and the $\mathrm{ABTS}^{+}$ethanol working solution $(100 \mu \mathrm{L})$. The mixture was stirred and allowed and left to stand for $10 \mathrm{~min}$ in the dark, after which the absorbance was measured at $734 \mathrm{~nm}$ against a blank. All determinations were performed in triplicate. The scavenging ability of the samples was expressed as the $\mathrm{IC}_{50}$ value, the effective concentration at which $50 \%$ of the ABTS radicals were scavenged.

2.7. Cell Culture. HUVECs were generous gift from Atherosclerosis Research Institute of Taishan Medical University of China. HUVECs were cultured in high-glucose DMEM medium supplemented with $10 \%$ FBS and $100 \mathrm{U} / \mathrm{mL}$ penicillin and $100 \mu \mathrm{g} / \mathrm{mL}$ streptomycin. Cells were grown and maintained in a humidified incubator at $37^{\circ} \mathrm{C}$ and $5 \% \mathrm{CO}_{2}$. All studies were performed using $80-90 \%$ confluent cells before treatment. To induce vascular endothelial damage, HUVECs were treated with designed concentrations of Ox-LDL $(20,40$, and $80 \mu \mathrm{g} / \mathrm{mL})$.

2.8. Cell Viability Assay. Cells were seeded in 96-well plates. After treatment with EEBP $(1.25,2.5$, and $5 \mu \mathrm{g} / \mathrm{mL})$ combined with Ox-LDL $(40 \mu \mathrm{g} / \mathrm{mL})$ for 3,6 , and $12 \mathrm{~h}$, cell viability was measured by SRB assay. Briefly, $100 \mu \mathrm{L} 10 \%$ trichloroacetic acid was used to precipitate cells at $4^{\circ} \mathrm{C}$ for $1 \mathrm{~h}$. After 5 washes in deionized water, the cells were stained with $50 \mu \mathrm{L}$ of $0.4 \%$ (W/V) SRB solution at room temperature for $20 \mathrm{~min}$ and washed five times with $1 \%$ acetic acid. $100 \mu \mathrm{L}$ of $10 \mathrm{mM}$ Tris base was used to dissolve the bound dye. The optical densities were measured at the wavelength of $492 \mathrm{~nm}$ using microplate spectrophotometer.

The viability (\%) was expressed as (OD of treated group/OD of Ox-LDL group) $\times 100 \%$. The viability of the OxLDL group was set at $100 \%$.

2.9. Acridine Orange (AO) and Hoechst 33258 Staining. $\mathrm{AO}$ and Hoechst 33258 were used to test the morphological changes of nuclei and apoptosis, respectively. At $6 \mathrm{~h}$, cells were stained with $\mathrm{AO}(5 \mu \mathrm{g} / \mathrm{mL})$ at room temperature for $5 \mathrm{~min}$ or stained with Hoechst $33258(10 \mu \mathrm{g} / \mathrm{mL})$ for 15 min. After that, cells were observed under a laser scanning confocal microscopy (Olympus FV1200, Japan) or a TE2000S fluorescence microscope (Nikon, Japan), respectively.

2.10. Real-Time PCR Analysis. After treatment with EEBP $(1.25,2.5$, and $5 \mu \mathrm{g} / \mathrm{mL})$ combined with Ox-LDL $(40 \mu \mathrm{g} / \mathrm{mL})$ for $6 \mathrm{~h}$, total RNA from HUVECs was extracted by RNA extraction kit (Carry Helix, China) in accordance with the manufacturer's protocol. The cDNA was synthesized from RNA with PrimeScript RT Kit (TaKaRa, Dalian, China) in accordance with the manufacturer's protocol. Quantitative PCR was performed with SYBR Premix EX Taq (TaKaRa, Dalian, China) using a Real-time PCR Detection System (Agilent StrataGene Mx3000, USA). The expression of the housekeeping gene $\beta$-actin was used to normalize the expression levels, and the results were expressed as $2^{-\Delta \Delta \mathrm{Ct}}$. The primer pairs were the following: HO- 1 (sense, $5^{\prime}$-TCTTGGCTGGCTTCCTTACC- $3^{\prime}$; antisense, $5^{\prime}$-GGATGTGCTTTTCGTTGGGG-3'), Nrf2 (sense, $5^{\prime}$-CAACTACTCCCAGGTTGCCC- $3^{\prime}$; antisense, $5^{\prime}$-AGTGACTGAAACGTAGCCGAA$3^{\prime}$ ), $\beta$-actin (sense, $5^{\prime}$-GCCGTTCCGAAAGTTGCCT-3'; antisense, $5^{\prime}$-CGCGGCGATATCATCATCCAT-3').

2.11. Immunofluorescence Assay. Immunofluorescence assay was performed as previous method [21]. In brief, cells were fixed in $4 \%$ paraformaldehyde $(\mathrm{w} / \mathrm{v})$ at room temperature for $15 \mathrm{~min}$ and then blocked with $5 \%$ donkey serum $(\mathrm{v} / \mathrm{v})$ for $20 \mathrm{~min}$. After adding the primary antibody-LC3B (1:100) and second antibody (1:200) (FITC-IgG), a laser scanning confocal microscope (Olympus FV1200, Japan) was used for fluorescence detection. Analysis used the Image-Pro Plus software (USA). Images are representative of three independent experiments.

2.12. Western Blotting Analysis. Western blotting analysis was performed as previous method [21]. After treatment with EEBP $(1.25,2.5$, and $5 \mu \mathrm{g} / \mathrm{mL})$ combined with OxLDL $(40 \mu \mathrm{g} / \mathrm{mL})$ for $6 \mathrm{~h}$, cells were washed twice with ice-cold PBS. Total cell lysates and nuclear extracts were prepared by cell lysis buffer and a nuclear extraction kit (Thermo Scientific, USA), respectively. Protein concentration was measured by the Bradford method. Equal amounts of protein were separated by $12-15 \%$ SDS-PAGE and then transferred to polyvinylidene difluoride (PVDF) membranes. $5 \%$ skim milk was used to block the membranes at room temperature for $1 \mathrm{~h}$. After that, the membranes were probed with primary antibodies $(1: 1000)$ at $4^{\circ} \mathrm{C}$ for $16 \mathrm{~h}$ and incubated with second antibodies (1:3000-5000) at $37^{\circ} \mathrm{C}$ for $1 \mathrm{~h}$ after three washes in TBST. The bands were visualized using an enhanced chemiluminescent detection kit (Thermo Electron Corp., USA).

2.13. Intracellular Reactive Oxygen Species (ROS) Analysis. To determine ROS production, cells were washed with basal DMEM medium after treatment and then stained with 0.5 $\mathrm{ml} \mathrm{DCHF}$ at $37^{\circ} \mathrm{C}$ for $30 \mathrm{~min}$ in the dark. After three washes with basal DMEM medium, the fluorescence was monitored with a confocal laser scanning microscope (Olympus FV1200, Japan). The photographs were representative of three independent experiments. Results were shown as the relative fluorescence intensity ratio compared with Ox-LDL group.

2.14. Mitochondrial Membrane Potential Measurement. JC-1 probe was used to test mitochondrial membrane potential. In brief, JC-1 probe was added to cells after EEBP treatment at $37^{\circ} \mathrm{C}$ for $15 \mathrm{~min}$ in the incubator, and cells were washed three times with basal DMEM medium. Then the fluorescence 
TABLE 1: HPLC-DAD/Q-TOF-MS analysis on EEBP.

\begin{tabular}{|c|c|c|c|c|}
\hline compounds & Retention time & {$[\mathrm{M}+\mathrm{H}]^{+}$} & EEBP (content mg/g) & regression equation \\
\hline kaempferol & 28.4 & 287.055 & 1.05 & $y=94864 x+129824$ \\
\hline caffeic acid & 17.2 & 181.0495 & 1.51 & $y=32392 x+22456$ \\
\hline p-coumaric acid & 20.22 & 165.0546 & 11.72 & $y=45243 x+73332$ \\
\hline pureonebio & 9.8 & 155.0339 & 0.34 & $y=23525 x+22623$ \\
\hline artepillin C & 34.7 & 301.1798 & 39.80 & $y=109286 x-69009$ \\
\hline naringenin & 27.0 & 273.0612 & 0.04 & $y=137541 x+229226$ \\
\hline ferulic acid & 21.4 & 195.0652 & 0.14 & $y=126715 x+159085$ \\
\hline
\end{tabular}

TABLE 2: The contents of TPC and TFC in EEBP and the free radical scavenging activities of EEBP.

\begin{tabular}{lcccc}
\hline sample & TPC $(\mathrm{mg} \mathrm{GAE} / \mathrm{g})$ & $\mathrm{TFC}(\mathrm{mg} / \mathrm{g})$ & $\mathrm{DPPH}_{\left(\mathrm{IC}_{50}\right)}$ & $\mathrm{ABTS}^{+}\left(\mathrm{IC}_{50}\right)$ \\
\hline EEBP & $111.40 \pm 4.78$ & $83.20 \pm 4.54$ & $179.11 \pm 4.09$ & $72.10 \pm 0.40$ \\
\hline
\end{tabular}

was monitored with a confocal laser scanning microscope (Olympus FV1200, Japan). Results were shown by ratio of red to green fluorescence as compared with the Ox-LDL group.

2.15. Statistical Analysis. Data are from at least three independent experiments and expressed as means \pm S.E.M. Statistical analysis involved the paired Student $t$ test and ANOVA with SPSS Ins (PASW Statistics 18). Differences were considered statistically significant at $P<0.05$.

\section{Results}

3.1. Components Identified in EEBP. A total of 7 compounds were identified and quantified in EEBP based on HPLCDAD/Q-TOF-MS analysis (Table 1). As shown in Table 1, $p$ coumaric acid (11.72 mg/g) and artepillin C (39.80 mg/g) were the dominant ingredients in EEBP.

3.2. Total Phenolic Contents (TPC), Total Flavonoid Contents (TFC), and Free Radical-Scavenging Activities of EEBP. The contents of TPC and TFC in EEBP were shown in Table 2. The content of TPC was $111.40 \pm 4.78 \mathrm{mg} \mathrm{GAE} / \mathrm{g}$, and TFC was $83.20 \pm 4.54 \mathrm{mg} / \mathrm{g}$. Some studies with ethanoic extracts of green propolis from the state of São Paulo have reported that the phenolic concentrations range from 49 to $100 \mathrm{mg} \mathrm{GAE} / \mathrm{g}$, and the flavonoid content was of $51.9 \pm 2.4 \mathrm{mg} / \mathrm{g}$ [22].

And the DPPH free racial scavenging activity $\left(\mathrm{IC}_{50}\right)$ of EEBP was $179.11 \pm 4.09$, and $\mathrm{ABTS}^{+}\left(\mathrm{IC}_{50}\right)$ was $72.10 \pm 0.40$, which was lower than Chinese propolis [23].

3.3. EEBP Enhanced the Cell Viability and Inhibited Apoptosis in Ox-LDL-Stimulated HUVECs. We firstly observed the effects of different concentrations of Ox-LDL (20,40, and $80 \mu \mathrm{g} / \mathrm{mL})$ on HUVECs and found that concentration of Ox-LDL treatment $(6 \mathrm{~h})$ within $20-80 \mu \mathrm{g} / \mathrm{mL}$ could inhibit cell survival of HUVECs resulting in decreased cell viability (Figure 1(a)). As a result, in our subsequent studies, we chose Ox-LDL $(40 \mu \mathrm{g} / \mathrm{mL})$ to induce endothelial cells damage. Our previous study showed that poplar propolis could protect HUVECs induced by Ox-LDL, and here we further demonstrated that Brazilian green propolis $(1.25,2.5$, and $5 \mu \mathrm{g} / \mathrm{mL})$ could improve cell viability in Ox-LDL-treated HUVECs at
3, 6, and 12 h. Furthermore, the protective effect of EEBP on Ox-LDL-stimulated HUVECs was more significant at $6 \mathrm{~h}$ (Figure 1(b)). AO and Hoechst 33258 staining also indicated that EEBP treatment obviously inhibited nuclear concentration and fragment caused by Ox-LDL (Figures 1(c) and $1(\mathrm{~d}))$.

To further confirm EEBP inhibited apoptosis in Ox-LDLstimulated HUVECs, the hallmarks of apoptosis, caspase 9, Bax, Bcl-2, caspase 3, and PARP levels were measured by western blotting analysis. After EEBP treatment, the antiapoptosis protein $\mathrm{Bcl}-2$ level significantly improved, and the level of proapoptosis protein Bax evidently decreased. Furthermore, the cleaved caspase 9, caspase 3, and PARP levels were significantly suppressed after EEBP treatment (Figure 2).

3.4. EEBP Suppressed Autophagy in Ox-LDL-Stimulated HUVECs. Besides EEBP suppressed apoptosis, we also wondered about the effect of EEBP on autophagy. As shown in Figure 3(a), when challenged with EEBP (1.25, 2.5, and $5 \mu \mathrm{g} / \mathrm{mL}$ ), cells stained with anti-LC3 antibody showed a significantly decreased punctuated pattern compared with Ox-LDL group (Figure 3(a)). Western blotting results also demonstrated that EEBP treatment obviously inhibited LC3 I to LC3 II shift. The levels of p62, the hallmark of autophagic flux, were obviously enhanced after EEBP treatment. Moreover, Beclin 1 and Atg7 levels which also are involved in autophagy also decreased during the process (Figures 3(b) and $3(\mathrm{c})$ ).

3.5. EEBP Ameliorated Oxidative Stress in Ox-LDL-Stimulated HUVECs. The Ox-LDL led to oxidative stress-induced HUVECs damage, which was regarded as an important step in the process of atherosclerosis. To find the protective mechanism of EEBP on Ox-LDL-stimulated HUVECs, we firstly tested the antioxidant genes levels of $\mathrm{Nrf} 2$ and HO1. Nrf2 is a key regulator in the cellular adaptive response to oxidative stress [24]. The activation of Nrf2 is involved in the protection of cells against oxidative stress. In $\mathrm{Ox}-$ LDL-stimulated HUVECs, we found that EEBP (2.5 and 5 $\mu \mathrm{g} / \mathrm{mL}$ ) could dramatically augment the mRAN expression of Nrf2 and its downstream signal molecular $-\mathrm{HO}-1$ at $6 \mathrm{~h}$ 


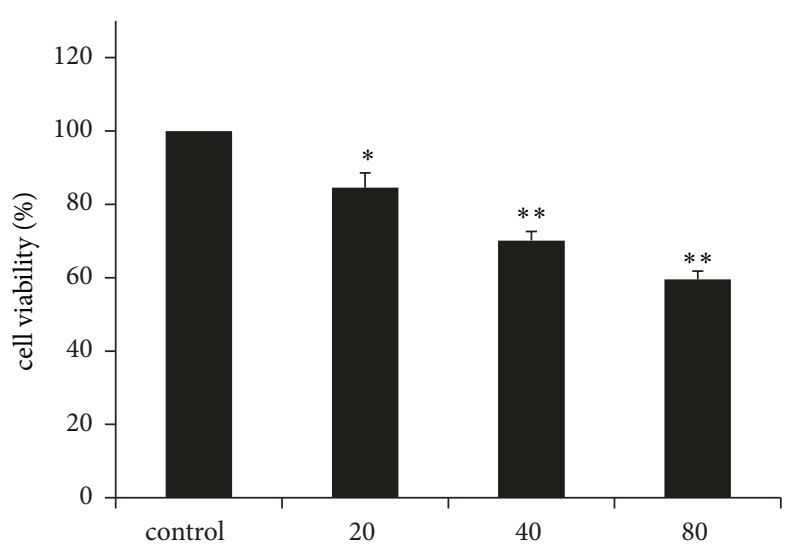

(a)

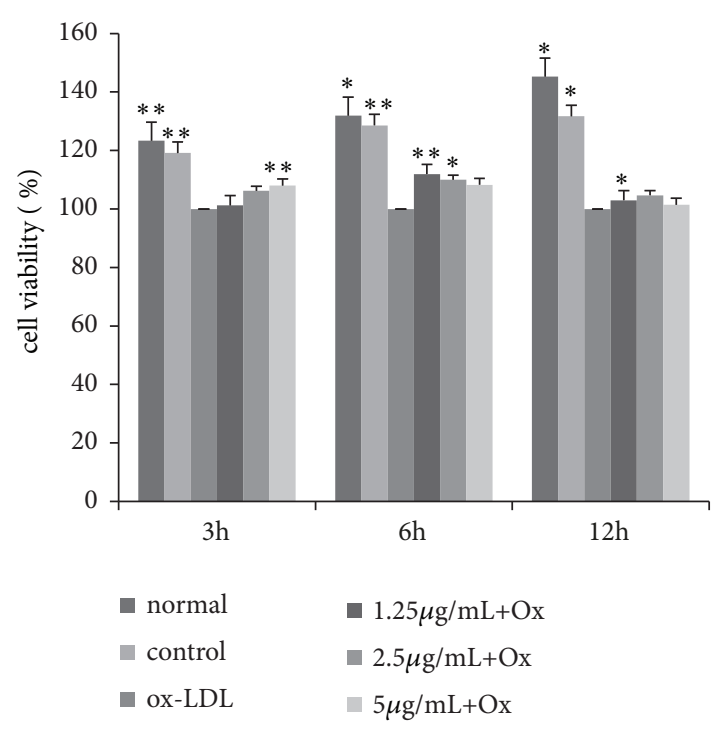

(b)
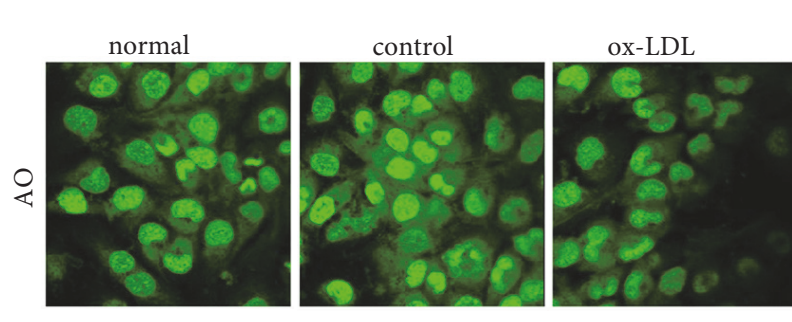

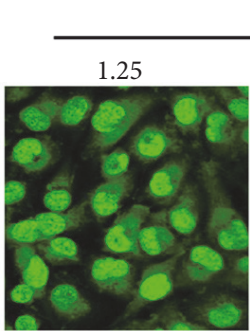

$\mathrm{EEBP}+\mathrm{Ox}-\mathrm{LDI}$

(c)

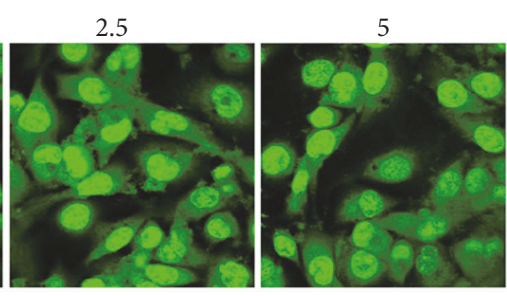

)
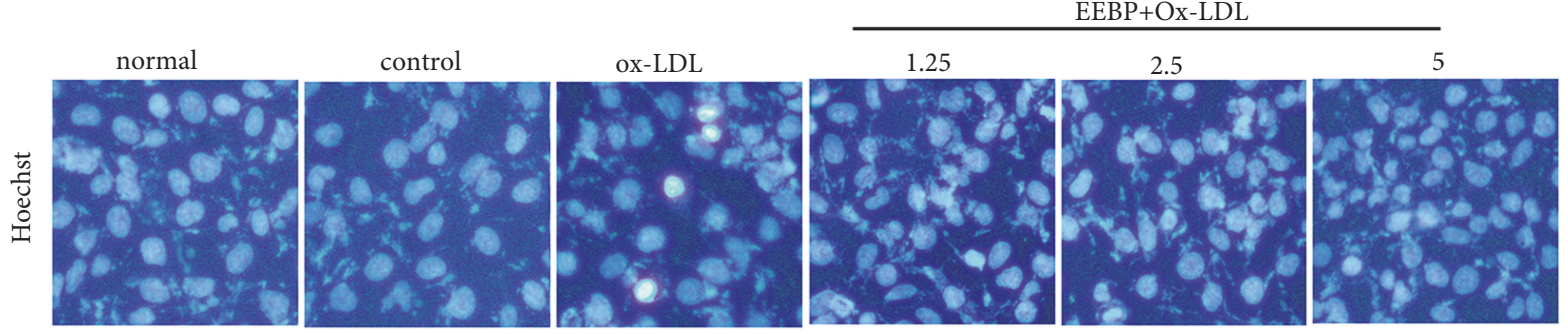

(d)

FIGURE 1: Effects of ethanol extracted Brazilian green propolis (EEBP) on cell viability in Ox-LDL treated HUVECs. (a), Effects of Ox-LDL $(20,40$, and $80 \mu \mathrm{g} / \mathrm{mL})$ on cell viability in Ox-LDL induced HUVECs at $6 \mathrm{~h}$. (b), Effects of EEBP $(1.25,2.5$, and $5 \mu \mathrm{g} / \mathrm{mL}) \mathrm{on}$ cell viability in Ox-LDL induced HUVECs for 3, 6, and $12 \mathrm{~h}$. Cell viability was tested by SRB assay and illustrated in column figures. $\left({ }^{*} P<0.05,{ }^{* *} P<0.01\right.$ vs Ox-LDL, $n=3$ ). Data are means \pm S.E.M. (c), AO staining showed treatment with EEBP depressed nuclear condensation and fragmentation in Ox-LDL induced HUVECs (200×). (d), Hoechst 33258 staining suggested that treatment with EEBP inhibited apoptosis in Ox-LDL induced HUVECs $(200 \times)$.

(Figure 4(a)). Western blotting results also demonstrated that EEBP treatment $(2.5$ and $5 \mu \mathrm{g} / \mathrm{mL})$ significantly enhanced HO-1 level (Figure 4(b)). Furthermore, nuclear fractions of EEBP treated cells presented a gradual increase in Nrf2 levels (Figures 4(b)-4(d)). Besides, EEBP treatment significantly inhibited ROS accumulation and elevated mitochondrial membrane potential in Ox-LDL-stimulated HUVECs (Figures $4(\mathrm{e})-4(\mathrm{~h}))$.

3.6. EEBP Activated PI3K/Akt/mTOR Signaling Pathway. Furthermore, activation of $\mathrm{Nrf} 2$ requires regulation of protein kinases, including the MAPK cascade, PI3K/Akt, and PKC signaling pathways. The phosphorylation of PI3K activated Akt and then mTOR can integrate upstream activating signals through PI3K/Akt pathway and become phosphorylated form, which negatively regulates autophagy [25]. To further determine the antioxidant mechanism of EEBP depressing oxidative stress induced by Ox-LDL, we investigated the effects of EEBP treatment on PI3K/Akt/mTOR signaling pathway. As shown in Figure 5, cells challenged with EEBP evidently increased the phosphorylation levels of PI3K, Akt, and mTOR, and the phosphorylation level of p70S6K, the 


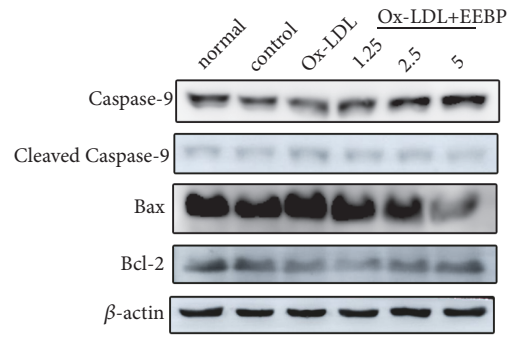

(a)

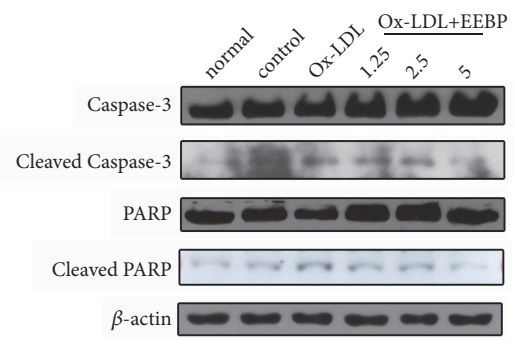

(c)
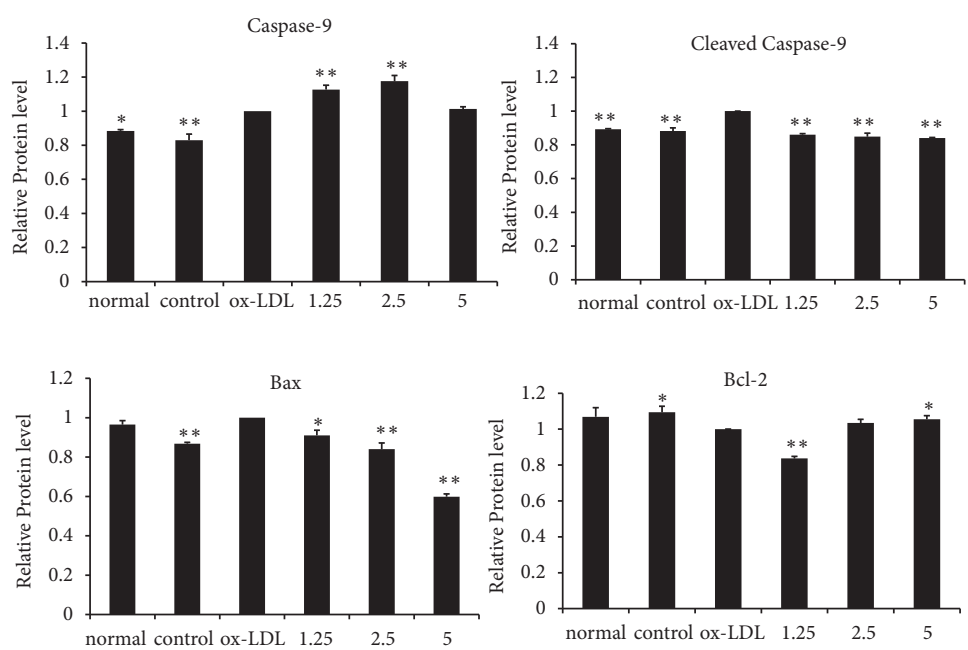

(b)
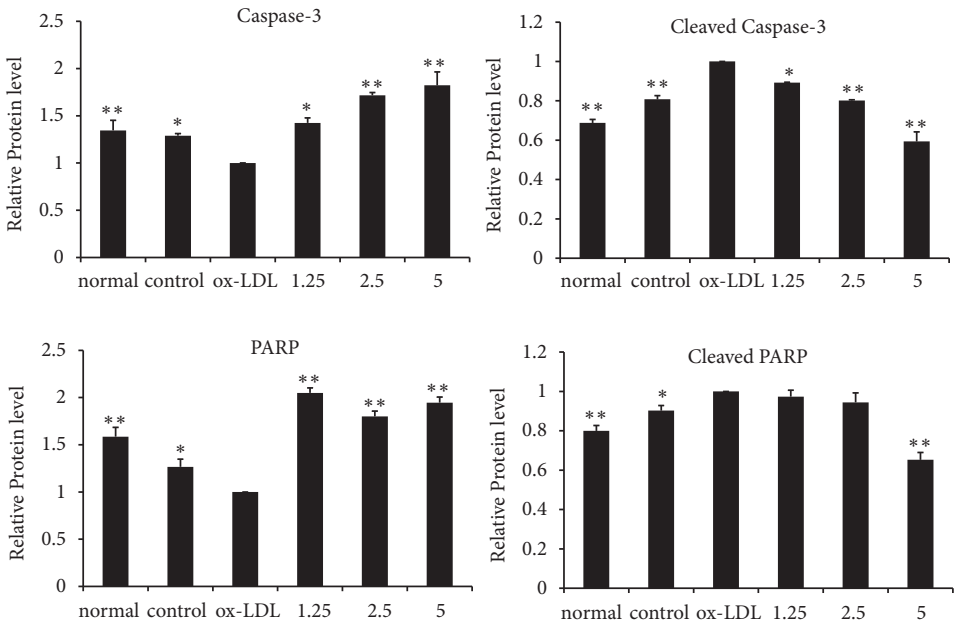

(d)

FIgURE 2: Treatment with EEBP inhibited apoptosis in Ox-LDL-stimulated HUVECs at 6 h. (a), Expression of caspase 9, cleaved caspase 9, Bax, Bcl-2, and $\beta$-actin in Ox-LDL induced HUVECs. (b), Quantification of relative protein expression quantity in Ox-LDL induced HUVECs at 6 h. (c), Expression of caspase 3, cleaved caspase 3, PARP, cleaved PARP, and $\beta$-actin in Ox-LDL induced HUVECs. (d), Quantification of relative protein expression quantity in Ox-LDL induced HUVECs at $6 \mathrm{~h}\left({ }^{*} P<0.05,{ }^{* *} P<0.01\right.$ vs Ox-LDL, $\left.\mathrm{n}=3\right)$. Data are means \pm S.E.M.

direct downstream target of mTOR, was also significantly elevated.

\subsection{EEBP Attenuated Oxidative Stress Was PI3K/AKT/mTOR} Dependent. Mounting evidence has demonstrated that activation of Nrf2 may be accompanied by Nrf2 nuclear translocation and bind with the ARE sequences. As shown in Figure 6(a), EEBP treatment enhanced Nrf2 accumulation in the nucleus, but Nrf2 level in the nucleus was significantly depressed after wortmannin treatment, a PI3K/Akt inhibitor (Figure 6(a)). Furthermore, the protein expressions of p-Akt, p-p70S6K, and HO-1 were inhibited in cells challenged with wortmannin as well as EEBP treatment (Figures 6(b) and 6(c)), indicating that EEBP attenuated oxidative stress was PI3K/Akt/mTOR dependent.

\section{Discussion}

In this study, we showed the antioxidant activity of the Brazilian green propolis is the key effects for its protecting in vascular endothelial cells against Ox-LDL challenge. Importantly, we have shown that Brazilian green propolis promoted activation of PI3K/Akt/mTOR pathway, further enhancing the cellular antioxidant system. This increased antioxidant activity attenuated apoptosis and inhibited autophagy of HUVECs induced by Ox-LDL.

The chemical constituents of propolis including poplar propolis and green propolis vary greatly according to plant origins and geographical and climatic features of the collection site $[26,27]$. Thus we tested the chemical constituents of this sample, and the predominating components in the sample used are $p$-coumaric acid and artepillin $\mathrm{C}$, which can 


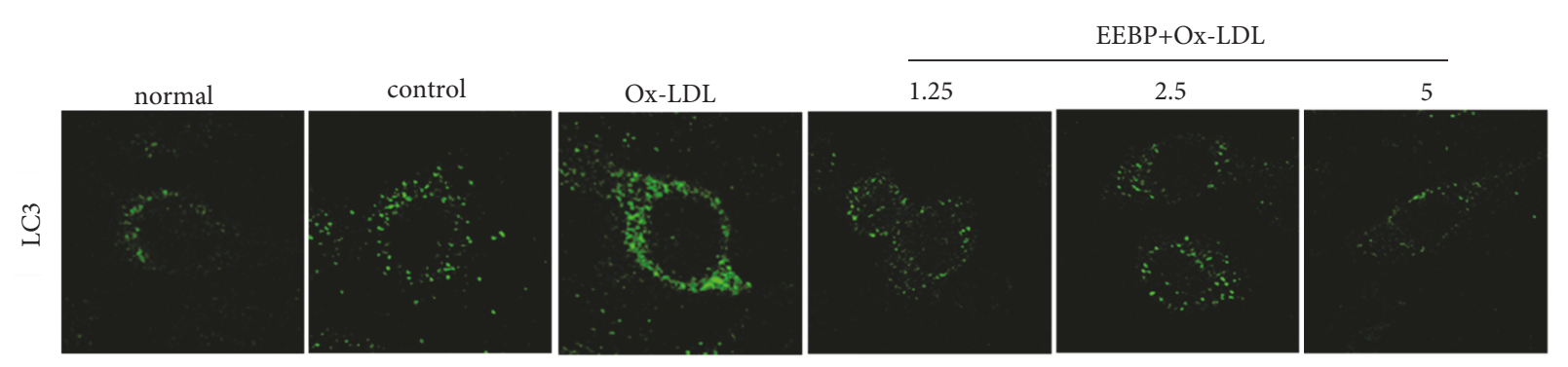

(a)

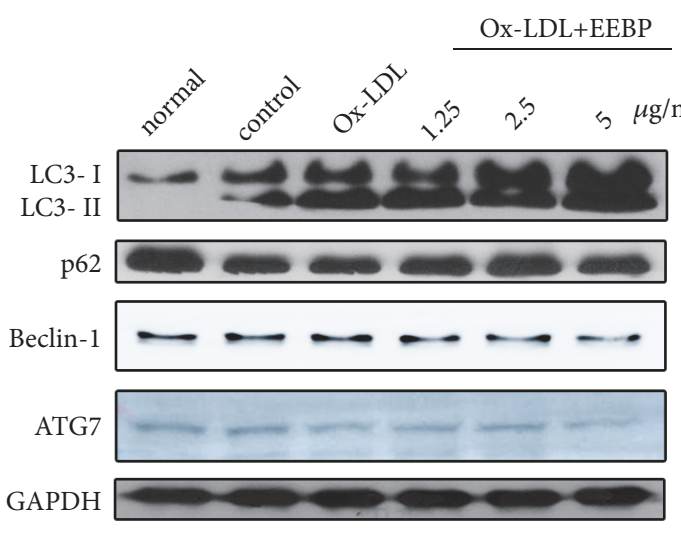

(b)
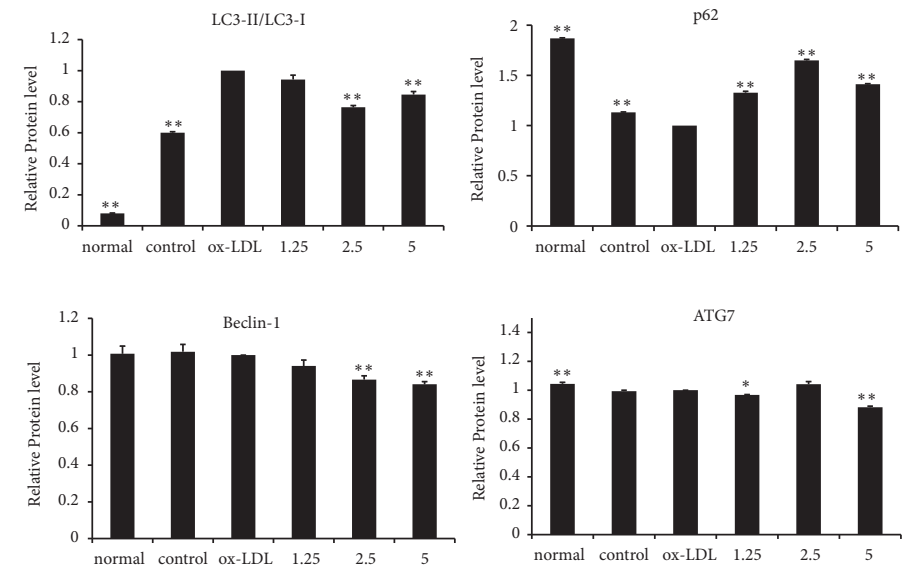

(c)

FIGURE 3: EEBP suppressed autophagy in Ox-LDL-stimulated HUVECs at 6 h. (a), Cells were stained with anti-LC3B antibody for immunostaining. Immunofluorescence graphs showed a decrease of endogenous punctuated LC3 after treatment with EEBP. (b), Expression of LC3B, p62, Beclin 1, and Atg7 in Ox-LDL induced HUVECs. (c), Quantification of relative expression quantity in Ox-LDL induced HUVECs at 6 h, respectively $\left({ }^{*} P<0.05,{ }^{* *} P<0.01\right.$ vs Ox-LDL, $\left.n=3\right)$. Data are means \pm S.E.M.

be seen as the markers of green propolis [27]. Moreover, Brazilian green propolis is rich in antioxidant polyphenols, which exerts excellent antioxidant activity.

Oxidative stress is an imbalance between prooxidants and antioxidants, and it has been postulated to be closely associated with cardiovascular diseases, including atherosclerosis. Nrf2 nuclear translocation augments expression of antioxidant-response element HO-1 and NQO1. HO-1 is induced by a variety of conditions associated with oxidative stress. Ishikawa et al. (2001) demonstrated that mildly oxidized LDL markedly induced HO-1 in human aortic endothelial damage [28]. Accumulating evidence demonstrates that natural plant-derived pharmacological modulators upregulate Nrf2/ARE to prevent chronic diseases including cardiovascular disease [29]. Here, BP, one of the plant-derived natural products, shows excellent antioxidant activities through attenuating ROS, protecting mitochondrial membrane potential, activating the antioxidant gene expression of Nrf2 and HO-1. Thus, Brazilian green propolis could improve redox conditions against oxidative stress to protect endothelium cells and further to prevent cardiovascular diseases. Additionally, various signaling cascades including mitogen-activated protein kinase are involved in the activation of Nrf2/HO-1 [30]. The present study showed Brazilian green propolis inhibiting oxidative stress was dependent PI3K/AKT/mTOR activation. Other studies have suggested that poplar type propolis stimulated antioxidant genes expression via p38/Erk-Nrf2 pathway [30]. There are more than 600 kinds of chemical compositions identified in propolis from different plant sources. The chemical compositions of poplar propolis and Brazilian green propolis vary greatly. The chemical constituents of poplar type propolis are mainly flavonoids, phenolic acids, and esters. However, $p$-coumaric acid and artepillin $\mathrm{C}$ are the dominant ingredients in Brazilian green propolis. The difference in chemical constituents may lead to the difference in the antioxidant mechanism.

The most inspiring aspect of the present study is that it explores the regulatory mechanism controlling vascular endothelial cells apoptosis and autophagy stimulated by Ox-LDL. Ox-LDL inhibits mTOR and induces apoptosis and autophagy in vascular endothelial cells [31]; Bcl/Baxcaspase9-caspase3 pathway maybe was involved in Ox-LDLinduced HUVECs apoptosis [32]. Many studies also have confirmed that propolis can modulate the expression of the Bcl-2 family genes, producing upregulation of the antiapoptotic Bcl-2 and downregulation of the proapoptotic Bax [33]. Here we found that Ox-LDL-induced HUVECs apoptosis could be inhibited by Brazilian green propolis, in which $\mathrm{Bcl}$ /Bax-caspase9-caspase3 pathway maybe was involved 

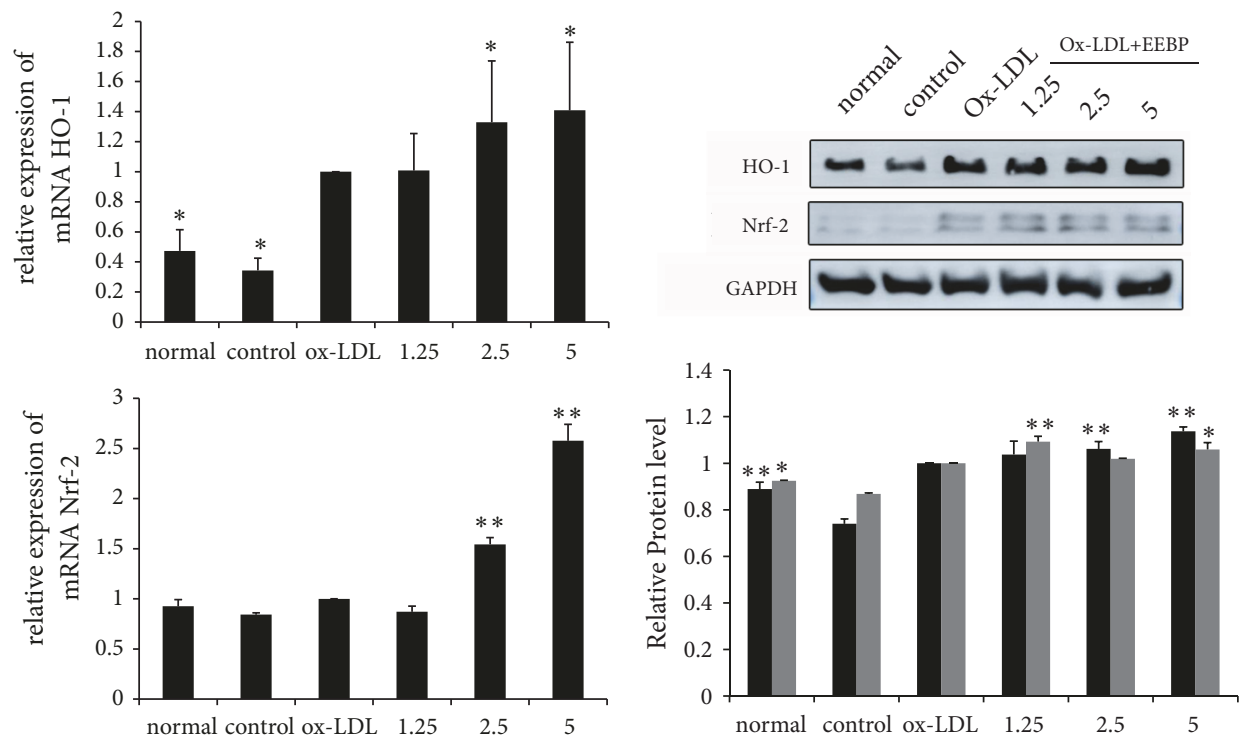

- $\mathrm{HO}-1$

- Nrf-2

(a)

(b)

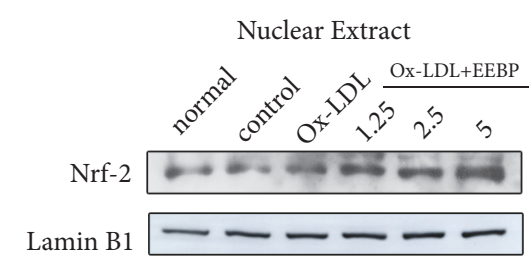

Cytoplasmic Extract

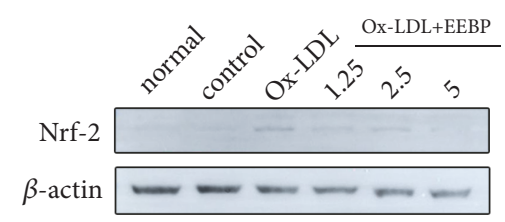

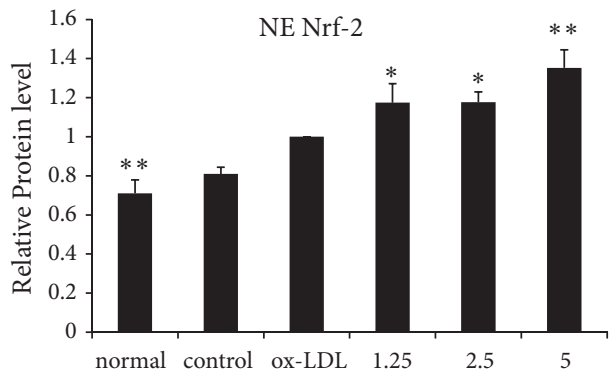

(c)

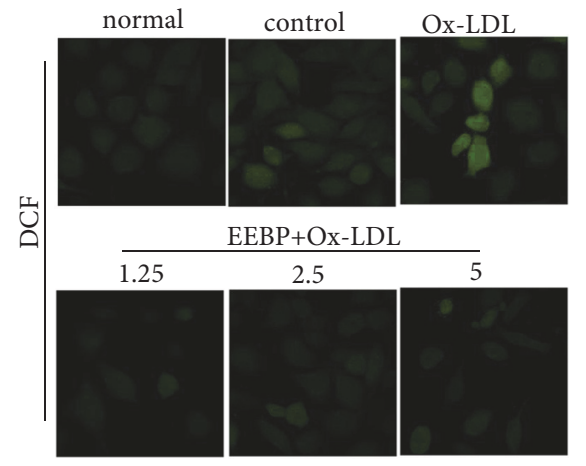

(e)

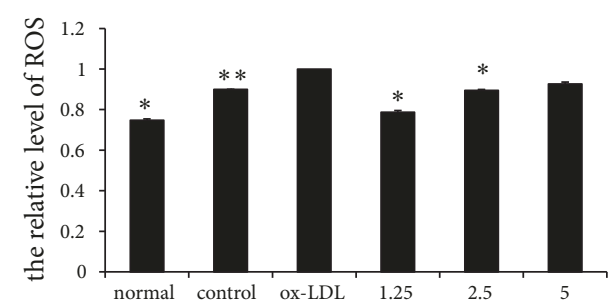

(f)

FIgURE 4: Continued. 


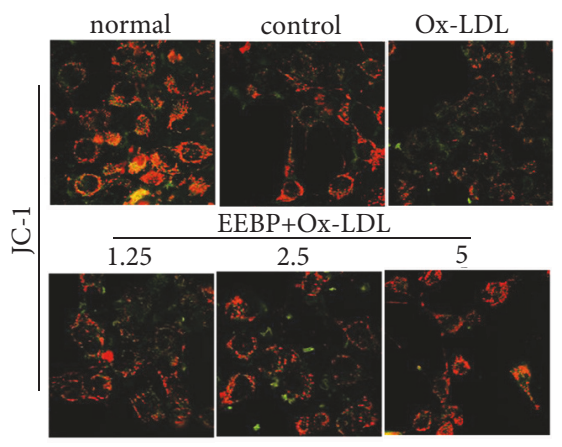

$(\mathrm{g})$

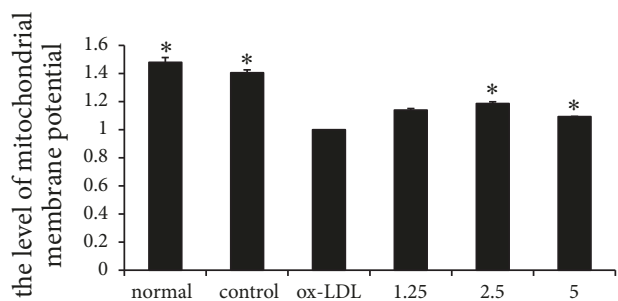

(h)

FiguRE 4: EEBP ameliorated oxidative stress in Ox-LDL-stimulated HUVECs at 6 h. (a), mRNA levels of HO-1 and Nrf2. (b), Expression of HO-1 and Nrf2 of total cell lysate in Ox-LDL-stimulated HUVECs. (c), Expression of Nrf2 of nuclear lysate in Ox-LDL-stimulated HUVECs. (d), Expression of Nrf2 of cytoplasmic lysate in Ox-LDL-stimulated HUVECs. (e), Fluorescent micrographs of ROS obtained in Ox-LDL induced HUVECs at 6 h. (f), Quantification of relative quantity of ROS in Ox-LDL induced HUVECs at 6 h. Values represent the relative fluorescent intensity per cell determined by laser scanning confocal microscopy. (g), Fluorescent micrographs of mitochondrial membrane potential obtained in Ox-LDL induced HUVECs at $6 \mathrm{~h}$. (h), Quantification of relative fluorescent intensity per cell determined by laser scanning confocal microscopy. Values are represented as ratio of red to green fluorescence $\left({ }^{*} P<0.05,{ }^{* *} P<0.01\right.$ vs Ox-LDL, n=3). Data are means \pm S.E.M.

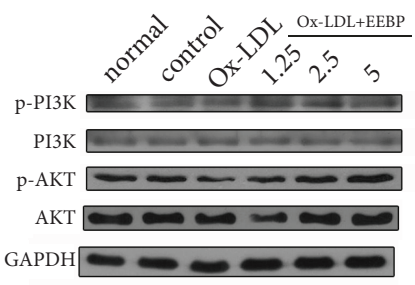

(a)

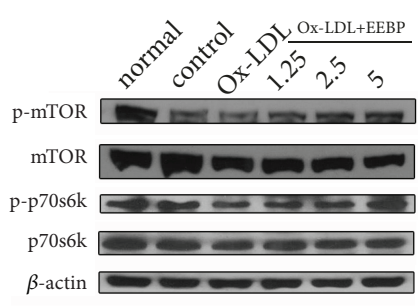

(c)
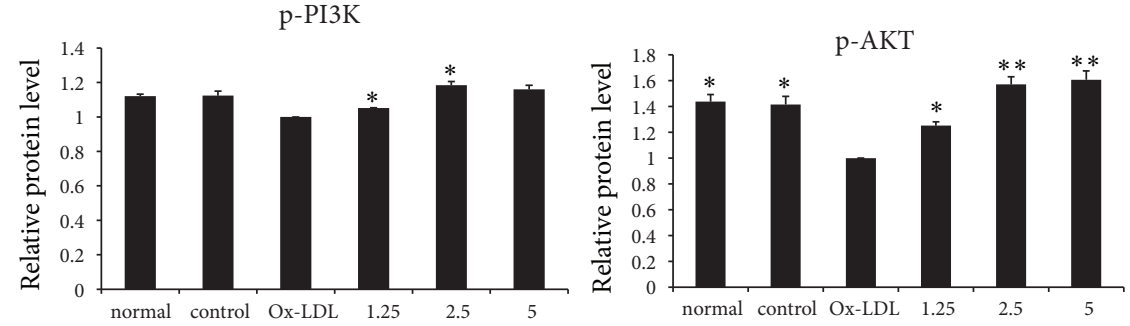

(b)
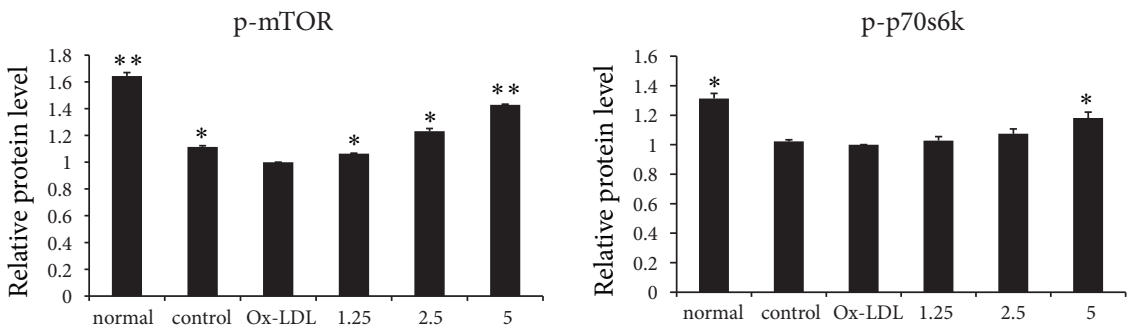

(d)

FIgURE 5: EEBP activated PI3K/Akt/mTOR signaling pathway. (a), Expression of Akt, p-Akt, PI3K, and p-PI3K after treatment with EEBP in Ox-LDL induced HUVECs at $6 \mathrm{~h}$, respectively. (b), Quantification of relative expression quantity of p-Akt and p-PI3K in Ox-LDL induced HUVECs at $6 \mathrm{~h}$, respectively. (c), Expression of mTOR, p-mTOR, p70S6K, and p-p70S6K after treatment with EEBP in Ox-LDL induced HUVECs at $6 \mathrm{~h}$. (d), Quantification of relative expression quantity of p-mTOR and p-p70S6K in Ox-LDL induced HUVECs at $6 \mathrm{~h}\left({ }^{*} P<0.05\right.$, ${ }^{* *} P<0.01$ vs $\mathrm{Ox}-\mathrm{LDL}, \mathrm{n}=3$ ). Data are means \pm S.E.M.

through increasing Bcl-2 and decreasing Bax levels and inhibited the activation of both caspases 9 and 3. On the other hand, autophagy is now known to become dysfunctional in atherosclerosis. Basal autophagy can protect plaque cells against oxidative stress, but excessively stimulated autophagy may lead to endothelium cells death to aggravate plaque rupture. We demonstrated here that the effects of Brazilian green propolis on autophagy might be associated with a mechanistic target of mTOR-dependent signaling pathway.

In summary, propolis alleviated Ox-LDL-induced HUVECs damage by suppressing apoptosis and autophagy. The underlying mechanism may, at least in part, involve activating PI3K/Akt/mTOR and enhancing antioxidant gene HO-1 and Nrf2 expression. Our study provides a potential 

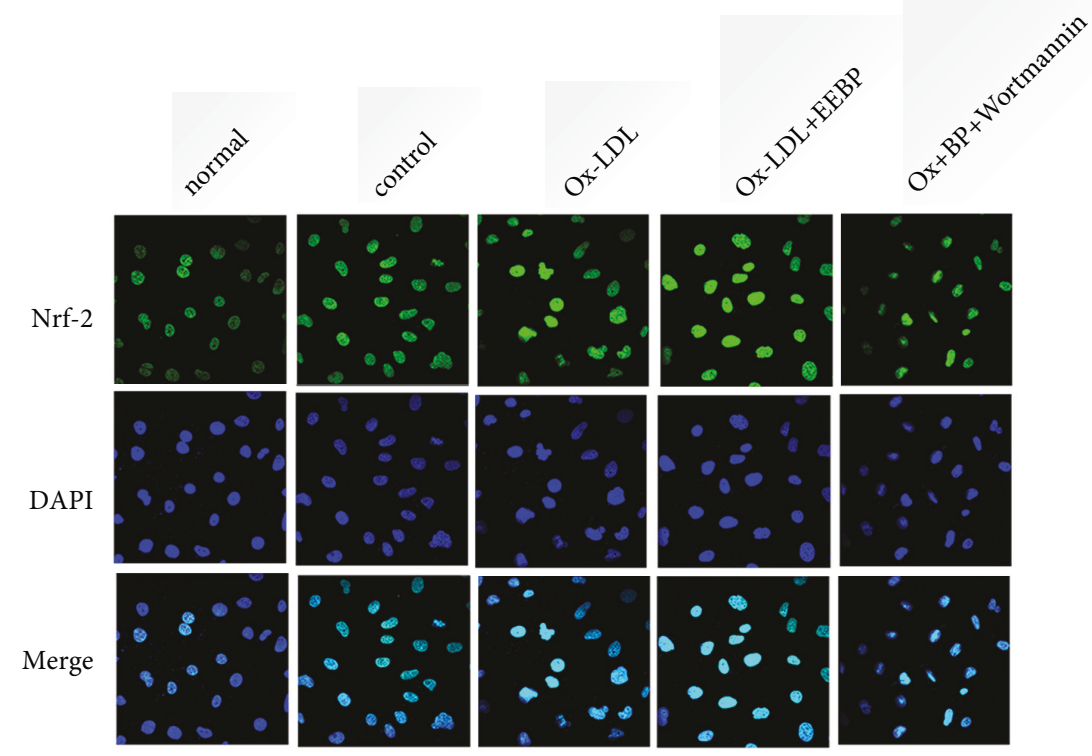

(a)

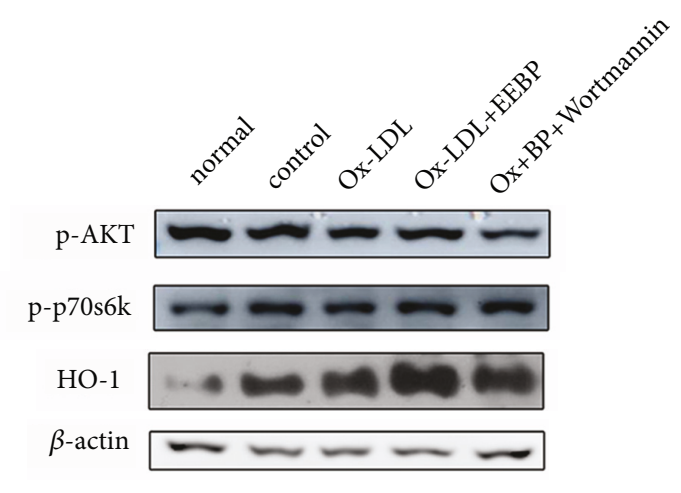

(b)

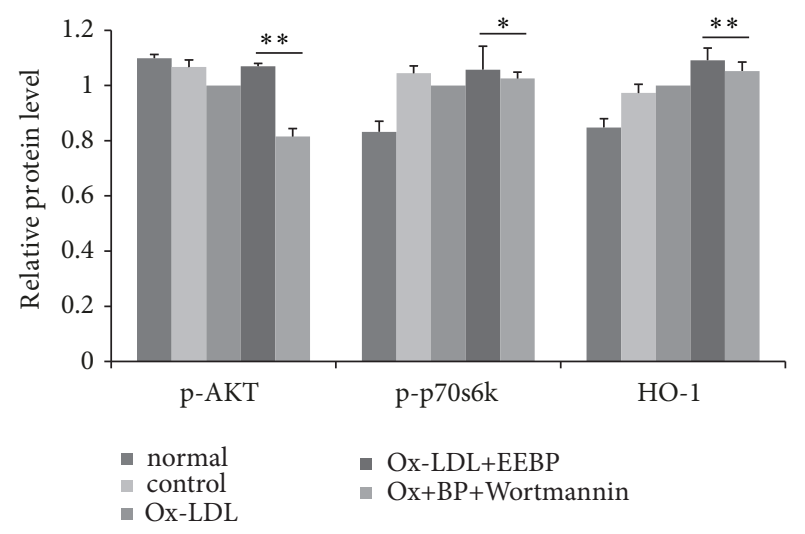

(c)

FIGURE 6: EEBP attenuated oxidative stress was PI3K/AKT/mTOR dependent. (a), Fluorescent micrographs of Nrf2 obtained in Ox-LDL induced HUVECs at $6 \mathrm{~h}$ after wortmannin treatment. (b), Expression of p-Akt, p-p70S6K, and HO-1 after wortmannin and EEBP treatment in Ox-LDL induced HUVECs at $6 \mathrm{~h}$, respectively. (c), Quantification of relative expression quantity of p-Akt, p-p70S6K, and HO-1 in Ox-LDL induced HUVECs at $6 \mathrm{~h}$, respectively $\left({ }^{*} P<0.05,{ }^{* *} P<0.01\right.$ vs Ox-LDL, $\left.\mathrm{n}=3\right)$. Data are means \pm S.E.M.

strategy for prevention and treatment of atherosclerosis and related cardiovascular diseases using natural bee propolis.

\section{Data Availability}

The data used to support the findings of this study are included within the article.

\section{Conflicts of Interest}

The authors declare no conflicts of interest.

\section{Authors' Contributions}

Wenwen Yuan and Huasong Chang contributed equally to this work.

\section{Acknowledgments}

This work was supported by the grant from the National Natural Science Foundation of China (No. 31672499), Shandong Province Higher Educational Science and Technology Program (J16LE21), and Shandong Province Modern Agricultural Technology System (SDAIT-24-05). 


\section{References}

[1] Y. Sohrabi, S. M. Lagache, L. Schnack et al., "mTOR-Dependent oxidative stress regulates oxldl-induced trained innate immunity in human monocytes," Frontiers in Immunology, vol. 9, no. 3155, 2019.

[2] L. Zhang, H. Zhang, X. Li et al., "Miltirone protects human EA.hy926 endothelial cells from oxidized low-density lipoprotein-derived oxidative stress via a heme oxygenase-1 and MAPK/Nrf2 dependent pathway," Phytomedicine, vol. 23, no. 14, pp. 1806-1813, 2016.

[3] C. Weber and H. Noels, "Atherosclerosis: current pathogenesis and therapeutic options," Nature Medicine, vol. 17, no. 11, pp. 1410-1422, 2011.

[4] J. W. Williams, C. Giannarelli, A. Rahman, G. J. Randolph, and J. C. Kovacic, "Macrophage biology, classification, and phenotype in cardiovascular disease: JACC macrophage in CVD series (part 1)," Journal of the American College of Cardiology, vol. 72, no. 18, pp. 2166-2180, 2018.

[5] A. V.Sima, C. S. Stancu, and M. Simionescu, "Vascular endothelium in atherosclerosis," Cell and Tissue Research, vol. 335, no. 1, pp. 191-203, 2009.

[6] P. Rajendran, T. Rengarajan, J. Thangavel et al., "The vascular endothelium and human diseases," International Journal of Biological Sciences, vol. 9, no. 10, pp. 1057-1069, 2013.

[7] J. Zhang, X. Cao, S. Ping, K. Wang, and J. Shi, "Comparisons of ethanol extracts of chinese propolis (poplar type) and poplar gums based on the antioxidant activities and molecular mechanism," Evidence-Based Complementary and Alternative Medicine, vol. 2015, Article ID 307594, 15 pages, 2015.

[8] X. Liu, L. Wang, J. Cai et al., "N-acetylcysteine alleviates H2O2induced damage via regulating the redox status of intracellular antioxidants in H9c2 cells," International Journal of Molecular Medicine, vol. 43, pp. 199-208, 2019.

[9] R. Hu, C. Xu, G. Shen et al., "Identification of Nrf2-regulated genes induced by chemopreventive isothiocyanate PEITC by oligonucleotide microarray," Life Sciences, vol. 79, no. 20, pp. 1944-1955, 2006.

[10] L. Staurengo-Ferrari, S. Badaro-Garcia, M. S. N. Hohmann, M. F. Manchope, T. H. Zaninelli et al., "Contribution of Nrf2 modulation to the mechanism of action of analgesic and antiinflammatory drugs in pre-clinical and clinical stages," Frontiers in Pharmacology, vol. 9, article 1536, 2018.

[11] X. Xiao, Z. Lu, V. Lin, A. May, D. H. Shaw et al., "MicroRNA miR-24-3p reduces apoptosis and regulates Keap1-Nrf2 pathway in mouse cardiomyocytes responding to ischemia/reperfusion injury," Oxidative Medicine and Cellular Longevity, vol. 2018, Article ID 7042105, 9 pages, 2018.

[12] T. Van-Assche, V. Huygelen, M. J. Crabtree, and C. Antoniades, "Gene therapy targeting inflammation in atherosclerosis," Current Pharmaceutical Design, vol. 17, no. 37, pp. 4210-4223, 2011.

[13] L. Baird and A. T. Dinkova-Kostova, "The cytoprotective role of the Keap1-Nrf2 pathway," Archives of Toxicology, vol. 85, no. 4, pp. 241-272, 2011.

[14] V. Bankova, "Chemical diversity of propolis and the problem of standardization," Journal of Ethnopharmacology, vol. 100, no. 12, pp. 114-117, 2005.

[15] S. Huang, C.-P. Zhang, K. Wang, G. Li, and F.-L. Hu, "Recent advances in the chemical composition of propolis," Molecules, vol. 19, no. 12, pp. 19610-19632, 2014.
[16] N. Yahfoufi, N. Alsadi, M. Jambi, and C. Matar, "The immunomodulatory and anti-inflammatory role of polyphenols," Nutrients, vol. 10, no. 11, article 1618, 2018.

[17] H. Chang, Y. Wang, X. Yin, X. Liu, and H. Xuan, "Ethanol extract of propolis and its constituent caffeic acid phenethyl ester inhibit breast cancer cells proliferation in inflammatory microenvironment by inhibiting TLR4 signal pathway and inducing apoptosis and autophagy," BMC Complementary and Alternative Medicine, vol. 17, article 471, 2017.

[18] H. Yang, Y. Dong, H. Du, H. Shi, Y. Peng, and X. Li, "Antioxidant compounds from propolis collected in Anhui, China," Molecules, vol. 16, no. 4, pp. 3444-3455, 2011.

[19] T. H. Ahn, Y. S. Yang, J. C. Lee et al., "Ameliorative effects of pycnogenol on carbon tetrachloride-induced hepatic oxidative damage in rats," Phytotherapy Research, vol. 21, no. 11, pp. 10151019, 2007.

[20] H. Shi, H. Yang, X. Zhang, and L. Yu, "Identification and quantification of phytochemical composition and anti-inflammatory and radical scavenging properties of methanolic extracts of Chinese propolis," Journal of Agricultural and Food Chemistry, vol. 60, no. 50, pp. 12403-12410, 2012.

[21] L. Wang, Z. Dong, B. Huang et al., "Distinct patterns of autophagy evoked by two benzoxazine derivatives in vascular endothelial cells," Autophagy, vol. 6, no. 8, pp. 1115-1124, 2010.

[22] N. S. S. Guimarães, J. C. Mello, J. S. Paiva et al., "Baccharis dracunculifolia, the main source of green propolis, exhibits potent antioxidant activity and prevents oxidative mitochondrial damage," Food and Chemical Toxicology, vol. 50, no. 3-4, pp. 1091-1097, 2012.

[23] J. Zhang, X. Shen, K. Wang et al., "Antioxidant activities and molecular mechanisms of the ethanol extracts of Baccharis propolis and Eucalyptus propolis in RAW64.7 cells," Pharmaceutical Biology, vol. 54, no. 10, pp. 2220-2235, 2016.

[24] K. Itoh, K. I. Tong, and M. Yamamoto, "Molecular mechanism activating Nrf2-Keap1 pathway in regulation of adaptive response to electrophiles," Free Radical Biology \& Medicine, vol. 36, no. 10, pp. 1208-1213, 2004.

[25] C. H. Jung, S. H. Ro, J. Cao, N. M. Otto, and D. H. Kim, "mTOR regulation of autophagy," FEBS Letters, vol. 584, no. 7, pp. 1287$1295,2010$.

[26] M. Keskin, Ş. Keskin, and S. Kolayli, "Preparation of alcohol free propolis-alginate microcapsules, characterization and release property," LWT- Food Science and Technology, vol. 108, pp. 8996, 2019.

[27] J. Coelho, S. I. Falcão, N. Vale, L. B. Almeida-Muradian, and M. Vilas-Boas, "Phenolic composition and antioxidant activity assessment of southeastern and south Brazilian propolis," Journal of Apicultural Research, vol. 56, no. 1, pp. 21-31, 2017.

[28] K. Ishikawa, D. Sugawara, X.-P. Wang et al., "Heme oxygenase1 inhibits atherosclerotic lesion formation in LDL-receptor knockout mice," Circulation Research, vol. 88, no. 5, pp. 506-512, 2001.

[29] H. Kumar, I. S. Kim, S. V. More, B. W. Kim, and D. K. Choi, "Natural product-derived pharmacological modulators of Nrf2/ARE pathway for chronic diseases," Natural Product Reports, vol. 31, no. 1, pp. 109-139, 2014.

[30] A. Paine, B. Eiz-Vesper, R. Blasczyk, and S. Immenschuh, "Signaling to heme oxygenase-1 and its anti-inflammatory therapeutic potential," Biochemical Pharmacology, vol. 80, no. 12, pp. 1895-1903, 2010.

[31] N. Peng, N. Meng, S. Wang et al., "An activator of mTOR inhibits oxLDL-induced autophagy and apoptosis in vascular 
endothelial cells and restricts atherosclerosis in apolipoprotein $\mathrm{E}^{-/-}$mice," Scientific Reports, vol. 4, article 5519, 2014.

[32] C.-Y. Wu, Z.-H. Tang, L. Jiang, X.-F. Li, Z.-S. Jiang, and L.-S. Liu, "PCSK9 siRNA inhibits HUVEC apoptosis induced by ox-LDL via Bcl/Bax-caspase9-caspase3 pathway," Molecular and Cellular Biochemistry, vol. 359, no. 1-2, pp. 347-358, 2012.

[33] M. Motomura, K. M. Kwon, S.-J. Suh et al., "Propolis induces cell cycle arrest and apoptosis in human leukemic U937 cells through Bcl-2/Bax regulation," Environmental Toxicology and Pharmacology, vol. 26, no. 1, pp. 61-67, 2008. 


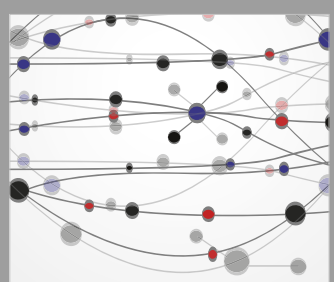

The Scientific World Journal
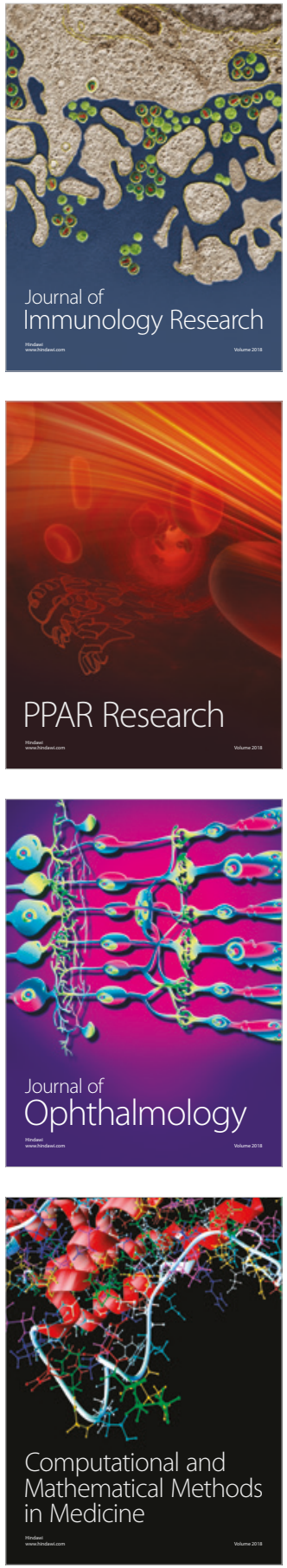

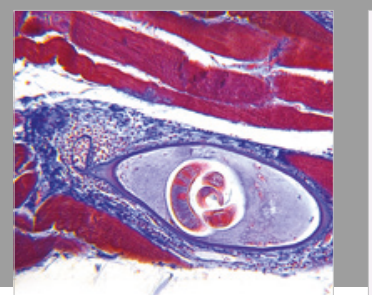

Gastroenterology Research and Practice

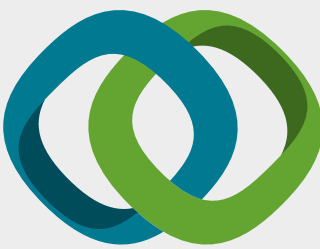

\section{Hindawi}

Submit your manuscripts at

www.hindawi.com
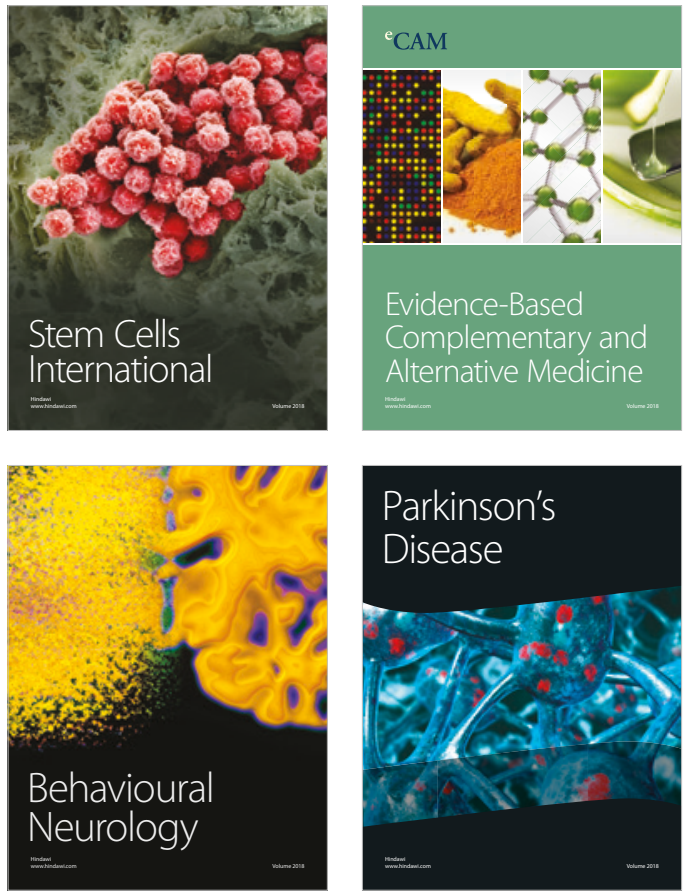

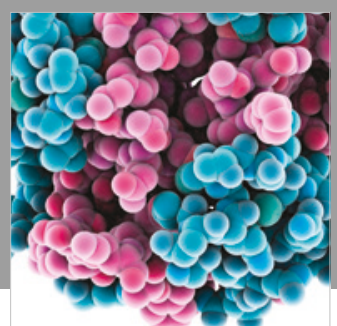

ournal of

Diabetes Research

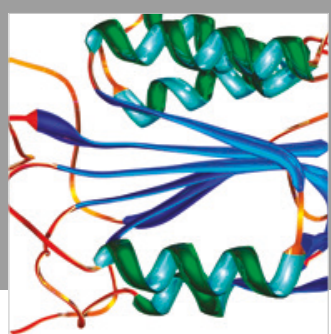

Disease Markers
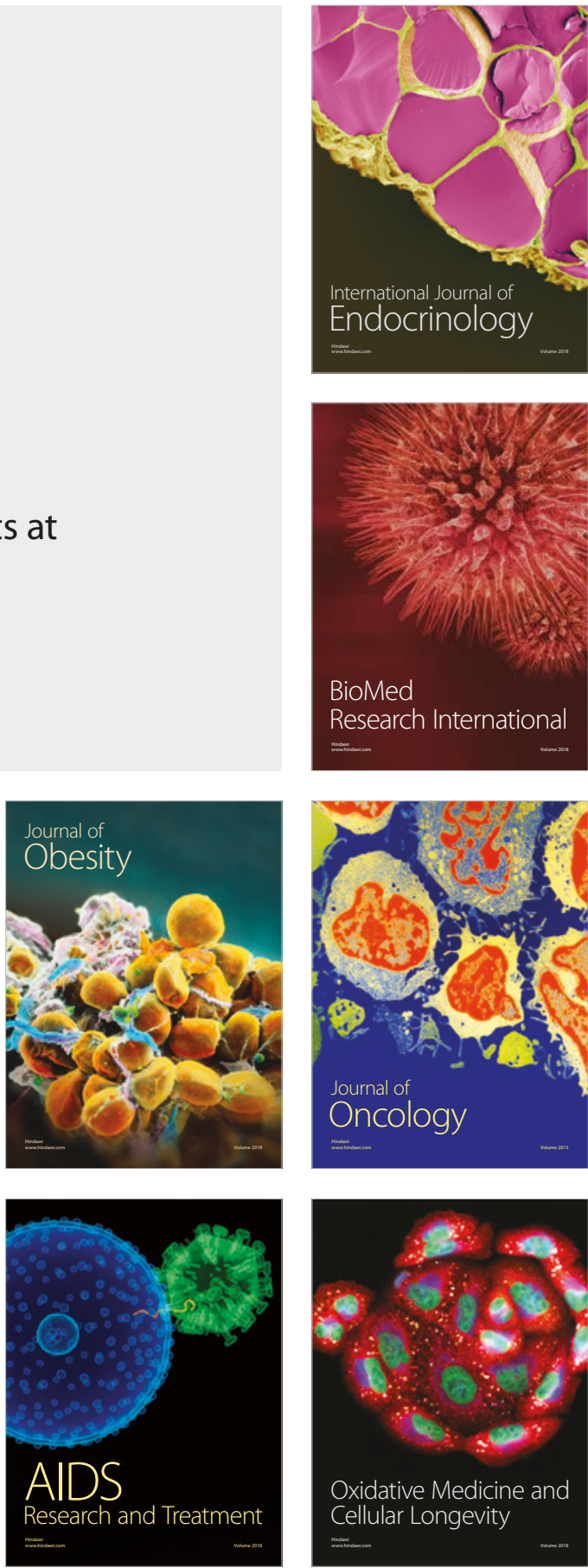